\title{
Study on Mutation Mechanism of Victim's Psychological Behavior State after Major Natural Disasters
}

\author{
Xuanhua Xu*, Yushi Liu, Zitao Zhang \\ School of Business, Central South University, Changsha 410083, China
}

\author{
ARTICLE INFO \\ Article History \\ Received 06 January 2020 \\ Accepted 15 April 2020 \\ Keywords \\ Major natural disaster \\ psychology behavior \\ mutation mechanism
}

\begin{abstract}
Aiming at the problem of victim's rational and irrational behavior during recovery stage in major natural disaster, this paper analyzed the victim's psychological and behavioral characteristics and influencing factors during recovery stage based on lots of literatures and an interview with victims. Besides, a mechanism chart of the formation of the victim's psychological behavior and a cusp catastrophe model are constructed. The catastrophe mechanism of the victim's psychological behavior during recovery stage is simulated under the influence of the physical demand factors and the emotional needs factors. The two different functions of the two demand factors are analyzed. The model is partially verified by the investigation data of the disaster area. Finally, the paper put forward some strategies to cope with victim's psychology and behavior during recovery stage based on the cusp catastrophe model analysis.
\end{abstract}

(c) 2020 The Authors. Published by Atlantis Press SARL.

This is an open access article distributed under the CC BY-NC 4.0 license (http://creativecommons.org/licenses/by-nc/4.0/).

\section{INTRODUCTION}

With the increasingly prominent problem of global climate change, the frequency of all kinds of natural disasters is increasing, and the scope of impact is becoming wider and wider. According to the statistics of the civil affairs bureau, all kinds of natural disasters in China have caused 243,533 million disasters, 1583 deaths, 6017 million emergency relocation in 2014, and the direct economic losses have reached 337,38 billion yuan [1]. Natural disasters not only cause a large number of casualties and economic losses, but also cause varying degrees of psychological trauma to the affected people, which may affect individual behavior in the short-term or even in the long-term [2]. Many cases have shown that anxiety in disaster scenarios can urge the affected children to make some aggressive behaviors [3], these experiences of negative psychological behaviors will increase the difficulty of rescue and resettlement. If it is not alleviated in time and effectively, it will accumulate gradually, and easily turn into illegal behavior, or even evolve into group events [4] and reduce the stability and safety of society [5,6]. Behavior analysis of the disaster victims plays an important role in crisis management, disaster emergency response and implementation of evacuation plan [7], and is also one of the core scientific issues in emergency management of public emergencies [8]. Therefore, in order to rescue effectively and block the evolution and upgrading of individual events, and scientifically formulate rescue strategies after the disaster, it is necessary to deeply analyze the mutation mechanism of individual psychological behavior state of the affected people after natural disasters.
Many researchers have studied the psychology and behavior of the people affected by climate change and natural disasters. Doherty and Clayton [9] analyzed three effects of climate change on people's psychology: direct psychological impact (ASD or PTSD); indirect psychological impact (decreased wellbeing); social psychological impact (social conflict). Norris et al. [10] analyzed more than 160 empirical studies on disasters from 1981 to 2001 and found that the occurrence of nature disasters would bring people some short- or long-term psychological problems, such as specific psychological injury, mental and physical disorders. Aiming at whether there is a correlation between natural disasters and suicide behavior, Kõlves et al. [11] has analyzed the existing empirical studies and found that different types of natural disasters have different effects on suicide rate, and suicide rate is mainly affected by economic conditions. $\mathrm{Hu}$ et al. [12] believed that people had panic behavior in evacuation and temporary resettlement after the disaster, and panic behavior was infectious, which made more affected groups panic. Helbing et al. [13] also simulated the irrational panic escape behavior of groups under the emergency. Panic psychology and irrational behavior are easy to lead to stampede events under emergency events, which are the important factors to increase the loss of life and property [14]. In addition, some studies have proved that people have prosocial behaviors and show resilience after disasters. Bonanno et al. [15] found that resilience is mainly related to income, social support and other factors of the affected people by questionnaire survey and multivariate analysis. van der Linden [16], Akerlof et al. [17] and other researchers also used empirical methods to explore the correlation between risk perception and social structure, economy and other control factors after natural disasters. These studies lay a theoretical and empirical foundation for exploring the mutation mechanism of the psychological and behavioral state of the victims. 
However, there are some deficiencies in the current researches on natural disasters and psychological behaviors of disaster victims. First, researchers only analyze whether natural disasters will cause people's psychological and behavioral abnormalities, and they pay more attention to the results of people's behavior after natural disasters, and lack researches of the process mechanism of psychological behavior changes of the victims which caused by natural disasters; second, the existing empirical methods assume that the control factors and the psychological behaviors of the victims are linear and continuous, and this assumption has limitations in the research of the real psychology of the victims. Vallacher and Nowak [18] analyzes that the social psychology is dynamic and complex, which is difficult and hard to describe with the traditional methods and empirical researches and needs to be further explained by the system theory. As an important branch of system theory, catastrophe theory can better analyze the system which is unknown by the internal function mechanism.

Catastrophe theory is a theory put forward by Thom [19], a French mathematician, which studies the phenomenon of system's jumping and discontinuity change caused by the continuous change of external control parameters in the system. Zeeman [21] made further research on catastrophe theory and proposed Zeeman mutation mechanism, and analyzed several characteristics of cusp mutation system: (1) The system has polymorphism, and with the change of control system parameters, the system will jump from one stable state to another; (2) The system is inaccessible, and there is no absolute stable state between different states of the system. In reality, it is inaccessible; (3) The system is divergent, two similar paths near the bifurcation set of control system change will make the system reach two completely different states; (4) The system is hysteretic, it will take some time for the system to recover to the original state after a disturbance change.

Catastrophe theory is a theory based on topology, bifurcation theory and stability theory. It directly deals with discontinuity without any special internal mechanism, which makes it particularly suitable for studying the system with unknown internal function and can effectively explain the "black box" problem. When the system has the above catastrophe characteristics, catastrophe theory can be used to explain [20]. Zeeman [21] and Stewart and Peregoy [22] applied catastrophe theory to the study of psychology and elaborated some specific hypotheses of catastrophe theory to describe people's attitude change. van der Maas et al. [23] also applied catastrophe theory to the mutation mechanism analysis of people's attitude change, and proved the feasibility of catastrophe theory model to describe attitude change with empirical data. Scott [24] gave an effective explanation for the clinical psychological phenomena that cannot be explained by other theories in clinical psychology, such as schizophrenia, emotional disorders, aggression, etc. using catastrophe theory. Flay [25] thinks that people's psychological process and social behavior cannot be simply expressed by gradient function, which satisfy some characteristics of cusp or butterfly mutation model, and summarizes the cusp mutation model is more suitable for describing people's behavior changes. Catastrophe theory can not only study social science problems [26], but also analyze the behavior of employees in enterprise management. $\mathrm{Xu}$ and $\mathrm{Bin}$ [27] etc. use catastrophe theory to analyze the anti-production behavior of employees in enterprises, conflict behavior [28,29], team knowledge sharing behavior [30], sudden change of employees' behavior [31], etc. Yiu and Cheung [32] analyzed the characteristics of employee conflict behavior in the construction industry and established a cusp catastrophe model. At the same time, the data showed that cusp catastrophe model was better than linear model and regression model to fit employee's conflict behavior. Chen [33] explained that the random cusp catastrophe model can well analyze the rational and irrational behaviors in social behaviors, and illustrated the application of the catastrophe model in social behaviors with examples.

To sum up, catastrophe theory can well analyze the changes of human psychological attitude, sudden changes of behavior and other social psychological behavior phenomena, which provides a theoretical basis and reference for the study of the catastrophe mechanism of the psychological behavior of the victims after natural disasters. However, the psychological behavior state of disaster victims is very different from that of ordinary emergencies and behavior change of employees, and has its own unique influence evolution mechanism. At present, there are few literatures to analyze the mutation mechanism of psychological behavior state of disaster victims, which needs further in-depth analysis. Therefore, based on the existing literatures and the investigations of the disaster area, this paper analyzes the characteristics and influencing factors of the psychological behavior state of the disaster victims, and based on this, constructs the catastrophe model of the disaster victims' psychological behavior state, explains the sudden change of the psychological behavior state of the disaster victims by using the catastrophe theory, and deeply analyzes the process change of the psychological behavior of the disaster victims, in order to effectively provide the theoretical basis of implementing the psychological intervention and rescuing in time after the disaster.

\section{ANALYSIS OF THE INFLUENCING FACTORS AND CHARACTERISTICS OF THE INDIVIDUAL PSYCHOLOGICAL BEHAVIOR STATE OF THE VICTIMS}

\subsection{Analysis of Characteristics of the Psychological and Behavioral State of the Victims}

In view of whether natural disasters will change the existing social and economic relations and lead to the abnormal behaviors of the affected people, Castillo and Carter [34] studied the altruistic behavior, trust and reciprocal behavior in 30 communities suffered from Hurricane Mitch in 1988 in Honduras. It was found that the mean value and variance of the behaviors of the affected people changed nonlinearly with the magnitude of the disaster impact, and moderate impact of natural disaster will improve people's cooperative and reciprocal and prosocial behavior, but some families suffer from economic pressure, such as the loss of shelter, the huge loss of living resources and so on, and in order to maintain their livelihood, they have uncooperative behavior, even conflict behavior. Kan [35] believes that people will have different psychological characteristics after disasters, sometimes they will bravely take responsibility, but sometimes they will choose to withdraw and escape. The dynamic disaster management model proposed by John leach also analyzes some special behaviors of victims in the impact stage 
of disaster. About 15\% of these behaviors are emotional out of control and overactive behavior, $75 \%$ are tense behavior and lack of initiative behavior, $10 \%$ are calm behavior and behavior with certain leadership [36]. Defu [37] analyzed the characteristics of farmers' disaster psychology and behavior, and found that people's psychological behavior has the characteristics of limited rationality and shortsightedness, and often shows some emotional behavior and extreme behavior in a short period of time. Huagui [38] believed that the individual behavior reaction of the victims was the external expression of their psychology. According to the rational degree of the victims' response to the disaster, the behaviors of the victims were divided into panic behavior and calm behavior. It was found that the behaviors of the victims were affected by the distance of psychological state, and the small change of the distance of state would lead to different behaviors, and further divided into six categories, such as Figure 1.

Through the analysis above, we can see that the psychological behavior state of the victims after the natural disaster has the following four characteristics, as shown in Table 1.

It can be seen that the characteristics of the psychological and behavioral state of the victims in the natural disaster scenario are in line with Zeeman's mutation characteristics. The cusp catastrophe model can be used to describe the mutation mechanism of the psychological and behavioral state of the victims.

\subsection{Analysis on the Influencing Factors of Individual Psychological Behavior of the Victims}

People's psychological behavior is affected by many factors under emergencies. Duoyong [39] divides the individual fear behavior into four categories: event itself, society, individual and the factors related to individual and disaster event, and establishes the individual fear model, and analyzes that individual fear mainly comes from psychological expectation. Qingguo and Xiaoyi [40] believes that human behavior in emergencies is a function of psychology, surrounding atmosphere and information, and analyzed the influence of various factors on human behavior. Some scholars also think that risk cognition is the key factor to determine people's psychological and behavioral states after disasters. The level of risk cognition determines different psychological and behavioral states of the victims [41], and people's risk cognition is determined by different factors, such as the influence on social trust, individual disaster experience, psychological distance and other variables [42-44].
However, behavioral science believes that people's various behaviors are caused by certain motives, which arise from various needs of people's bodies [45]. In order to satisfy various needs, people need to determine their own behavior goals, and then take a series of actions. Huijuan et al. [46] conducted a study on people's psychological problems after the Tangshan earthquake through more than 2000 questionnaires, and found that people's material needs were extremely intense after the disaster, it was because that natural disasters had greater destructive power on people's living conditions than other emergencies, and survival instinct urged people to pay more attention to material needs. At the same time, it is found that people still have psychological needs to be comforted and concerned in a long time after the disaster. From July to August in 2013, the research group went to Lushan County, the severely affected area of Yaan earthquake, for field investigation. The investigation time was three months after the Yaan earthquake. The victims' mood was basically stable and in the post disaster recovery period. Through interviews and individual questionnaires, it is concluded that people's psychological distress was mainly caused by economic loss. Although the government gave some subsidies, it was far from enough that can make up for the losses caused by the earthquake. Although people's emotions gradually return to normal after the disaster, we find that more than $80 \%$ of the victims still have anxiety, panic and other emotions through the post-traumatic stress disorder self-assessment table, and they cannot invest in the post disaster reconstruction work well. They are eager for emotional communication between people and have certain prosocial behavior. According to the survey data,

Table 1 Characteristics of victims' psychology and behavior under natural disasters scenarios

\begin{tabular}{|c|c|}
\hline $\begin{array}{l}\text { Behavior } \\
\text { characteristics } \\
\text { of victims }\end{array}$ & Specific description \\
\hline 1. Bimodality & $\begin{array}{l}\text { After the disaster, people's psychological behavior state } \\
\text { is only rational and irrational, which is especially } \\
\text { embodied in the rational behavior of prosocial } \\
\text { behavior and reciprocal cooperation; the irrational } \\
\text { behavior of conflict, distrust and panic, etc. }\end{array}$ \\
\hline 2. Unreachability & $\begin{array}{l}\text { After the disaster, people's behavior is either rational } \\
\text { or irrational, there is no intermediate state, and the } \\
\text { change of people's behavior is nonlinear. }\end{array}$ \\
\hline 3. Bifurcation & $\begin{array}{l}\text { When people's behavior state is in critical equilibrium } \\
\text { state, small change of state distance will lead to } \\
\text { people's different behaviors. }\end{array}$ \\
\hline 4. Hysteresis & $\begin{array}{l}\text { It will take some time for people to change from irra- } \\
\text { tional behavior to rational behavior after disaster. }\end{array}$ \\
\hline
\end{tabular}

Behavior

characteristics Specific description

is only rational and irrational, which is especially embodied in the rational behavior of prosocial behavior and reciprocal cooperation; the irrational or irrational, there is no intermediate state, and the state, small change of state distance will lead to tional behavior to rational behavior after disaster.

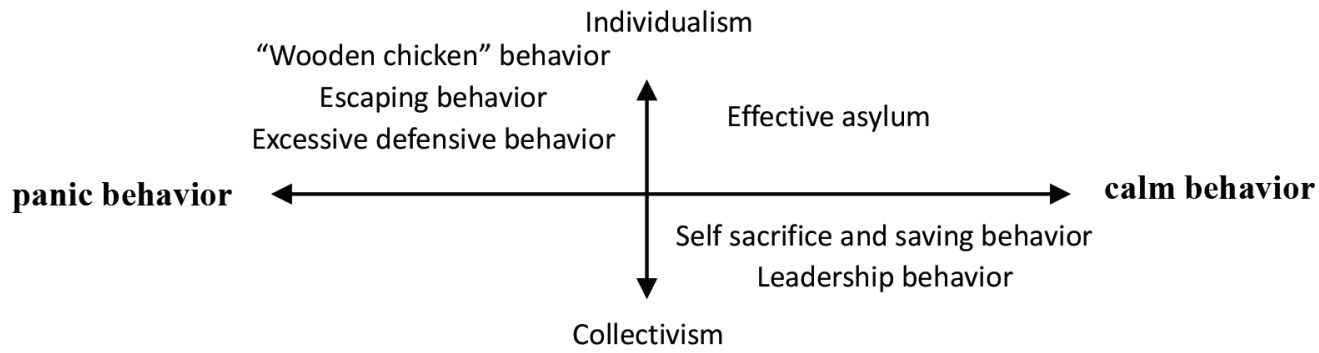

Figure $1 \mid$ Victims' behavioral response types. 
the needs of people in the post disaster recovery period are mainly two aspects: material and emotional needs. Through the material needs to satisfy the food, clothing, housing, transportation and life safety after the disaster, through the emotional needs to satisfy their sense of destination, eliminate the loneliness and depression after the disaster. The satisfaction degree of these two needs determines the risk cognition level of the affected people, and then determines the degree of panic and the rational degree of behavior. Risk cognition plays an intermediary role between needs and psychological behavior. According to the literature analysis and field survey summary above, the influencing factors of the psychological behavior of the victims under the natural disaster scenario are shown in Table 2.

\subsection{Analysis on the Formation Mechanism of Individual Psychological Behavior Changes of Victims}

In this paper, the individual psychological behavior of the victims is defined the psychological behavior of the victims in the recovery period after natural disasters. Based on the literature analysis and field research above, it can be seen that the material and emotional demand factors in this period will affect people's psychological cognitive evaluation, and then determine people's behavior. The psychological behavior of the victims may suddenly change between panic and calm behavior. This sudden change is caused by the mutation of distance perception of people's psychological state. The occurrence of natural disasters will break people's existing psychological balance state, resulting in a state distance [37]. When the state distance exceeds a certain threshold, people's psychological behavior will be in different states, resulting in a kind of jumping change. Based on Huagui's psychological behavior framework, this paper puts forward a change mechanism model of the psychological behavior of victims under natural disasters, as shown in Figure 2.

According to the formation mechanism model, there are two kinds of relatively stable psychological behavior states of the victims after natural disasters: panic and calm behavior. Panic behavior is a negative steady state. In this state, the disaster victims will have fear, quarrel with other disaster victims, conflict behavior, and even plunder materials and other risk behaviors that threaten social stability and order. However, when the psychological state distance of the victims gradually reduces to the psychological perception threshold, people's behavior may suddenly turn into calm behavior, such as actively participating in the post disaster rescue and reconstruction work, helping other victims and other prosocial behaviors.

Table 2 Factors of victims' psychology and behavior under natural disaster scenario

\begin{tabular}{lll}
\hline Influencing factors & Specific description & References \\
\hline Material demand factors & $\begin{array}{l}\text { To meet the basic needs of the affected people in terms of } \\
\text { clothing, food, housing, transportation and medical and } \\
\text { health care, mainly to maintain the basic life and life safety } \\
\text { of the victims. }\end{array}$ & $\begin{array}{c}\text { Research on the disaster area of Lushan County in Sichuan } \\
\text { Yaan earthquake in 2013 [46]; Tangshan earthquake } \\
\text { related psychological problems [47]; "Sangmei" typhoon } \\
\text { psychological influencing factors [48]; connotation mode } \\
\text { of disaster relief demand }\end{array}$ \\
$\begin{array}{ll}\text { Emotional demand factors } \\
\text { Comfort and psychological guidance from mental health } \\
\text { personnel, volunteers, relatives and friends, which is a } \\
\text { kind of psychological comfort demand. }\end{array}$ & $\begin{array}{l}\text { The process of processing, filtering and decoding signals } \\
\text { Telated risk to form a self-understanding of risk and plays } \\
\text { an important role in promoting people's risk behaviors. }\end{array}$ \\
\hline
\end{tabular}

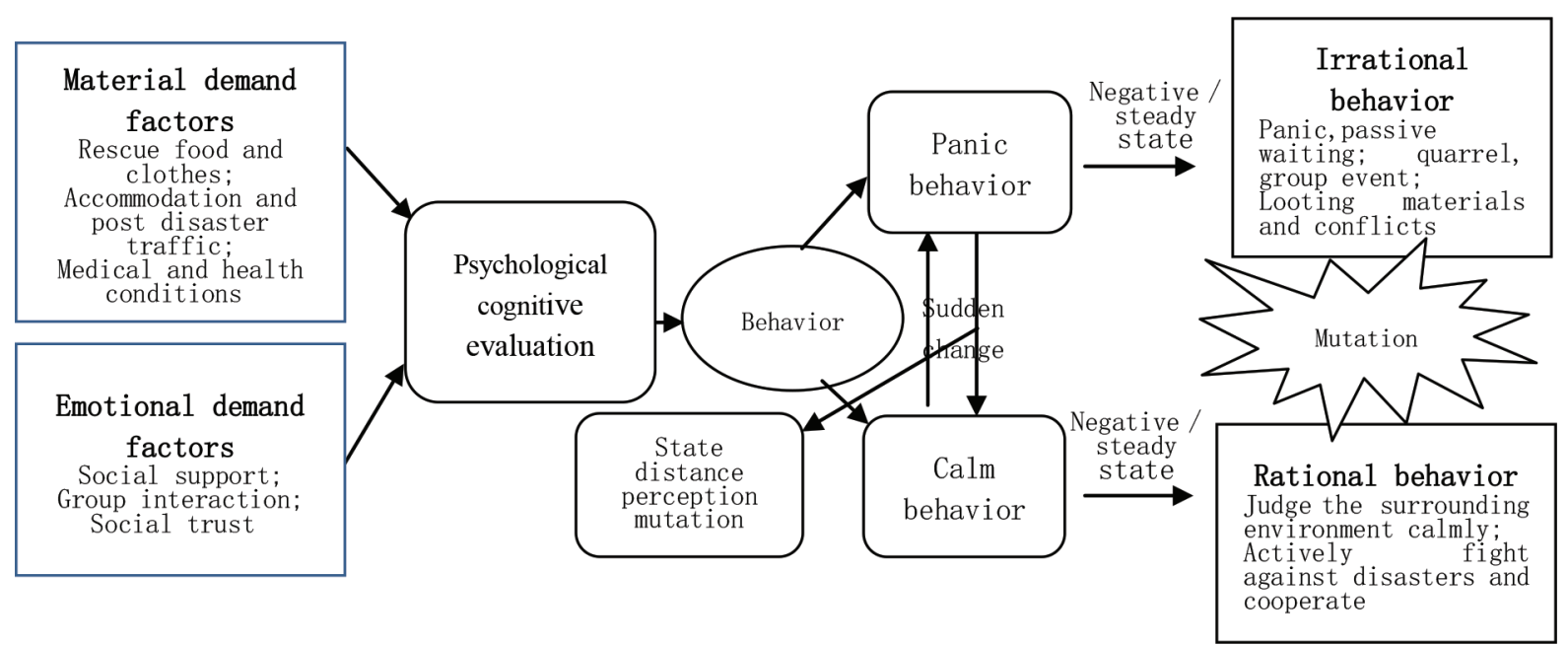

Figure 2 Formation mechanism for individual victim's psychological behavior changes during the recovery stage of natural disasters. 


\section{ESTABLISHMENT OF CUSP CATASTROPHE MODEL OF INDIVIDUAL PSYCHOLOGICAL BEHAVIOR AND SIMULATION ANALYSIS OF MUTATION MECHANISM}

\subsection{Construction of Cusp Catastrophe Model of Individual Psychological Behavior of Victims}

According to the formation mechanism of the individual psychological behavior state of the disaster victims, the individual psychological behavior state of the disaster victims can be regarded as the conjugates of material demand factors and emotional demand factors after the disaster. The individual psychological behavior $x$ of the victims is regarded as the state variable, and the satisfaction degree $u$ of the material demand factor and the satisfaction degree $v$ of the emotional demand factor are regarded as the control variables to control the individual psychological behavior of the victims. The individual psychological behavior $x$ is measured by the perception degree of psychological state, $u, v, x \in[-1,1] . V$ represents the potential function of the cusp catastrophe model of individual psychological state behavior of the victims [19], as shown in formula (1).

$$
V(x, u, v)=x^{4}+u x^{2}+v x
$$

The psychological behavior surface $M$ of the victims is the set of equilibrium points of the catastrophe model, i.e., the equilibrium surface of the catastrophe model, as shown in formula (2).

$$
M=\frac{\partial V(x, u, v)}{\partial x}=4 x^{3}+2 u x+v=0
$$

The set of singularities $n$ is the second derivative of potential function $V$, as shown in formula (3).

$$
N=12 x^{2}+2 u=0
$$

The catastrophe area $B$ of the psychological behavior of the victims is the set of bifurcation points of the catastrophe model, which is the solution obtained by the simultaneous elimination of $x$ by formulas (2) and (3), as shown in formula (4).

$$
B=8 u^{3}+27 v^{2}=0
$$

Formula (2) is a cubic equation, which has either one real root or three real roots. The number of real roots is determined by the determination formula $\Delta$ :

$$
\Delta=8 u^{3}+27 v^{2}
$$

Formula (2) is a equilibrium surface equation of individual psychological behavior state of the victims. Assuming that the satisfaction degree of material and emotional needs and the perception degree of psychological state of the victims are the values between the intervals $[-1,1]$, the greater the satisfaction degree of material and emotional needs is, the smaller the perception degree of psychological state is. According to formula (2), Matlab is used to simulate the influence of continuous changes of control variables between the intervals $[-1,1]$ on the state variables. Random values of $u$ and $v$ in $[-1,1]$ interval is determined by rand function, a set of data is a set of $u$ and $v$, i.e., $(u, v)$, randomly composed of 1000 data. In order to satisfy the formula (2), the perception of mental state $x$ also changes in turn. Finally, the equilibrium surface of the cusp catastrophe model of the individual psychological state of the victims can be obtained as shown in Figure 3. Then, according to this method, use formula (4) to get the bifurcation set of cusp catastrophe of the individual psychological behavior of the victims, i.e., the projection of the fold surface in Figure 3 on the control surface, as shown in Figure 4. When $\Delta>0$, formula (2) has only one real root. The continuous change of control variables $u$ and $V$ will cause the stable change of state variable $x$, and the psychological behavior of the victims will be in a stable state. When $\Delta=0, u$ and $v$ satisfying formula (2) have the same real roots, even when $u=v=0$, the three real roots are the same. At this time, the psychological behavior of the victims is in a critical stable state. When $\Delta<0$, the three real roots of formula (2) are not the same. It can also be seen from Figures 3 and 4 that the psychological behavior of the victims is

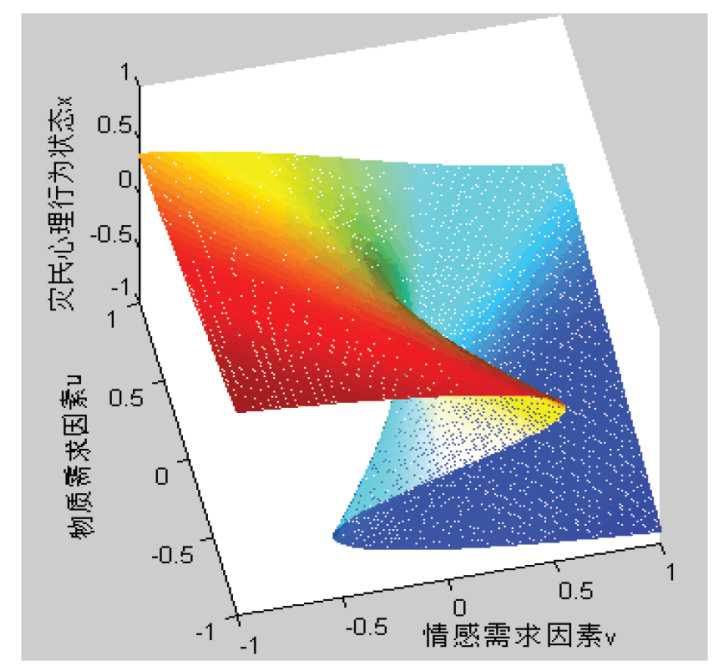

Figure 3 The cusp catastrophe model equilibrium of individual victim's psychological behavior.

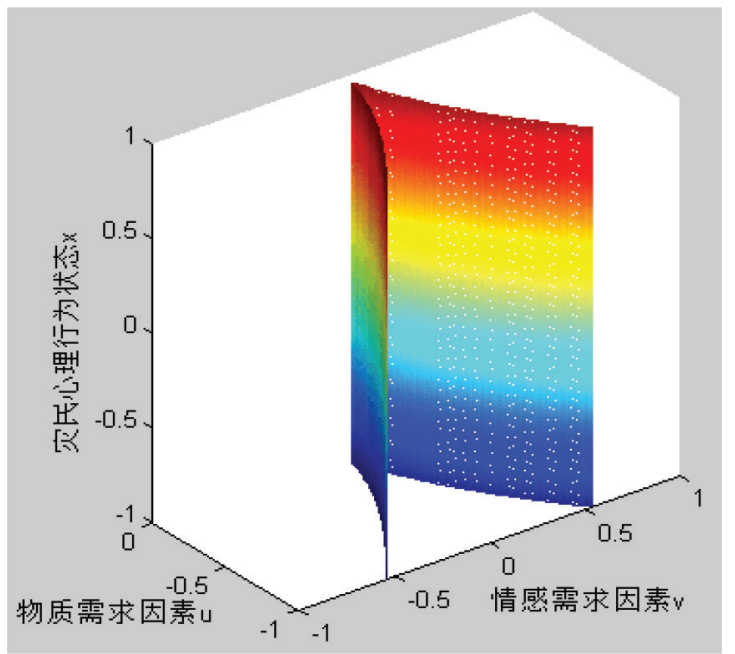

Figure $4 \mid$ The bifurcation set of cusp catastrophe model of individual victim's psychological behavior. 
unstable at this time, which is also the mutation of the psychological behavior of the victims at this time [52].

\subsection{Mechanism Analysis of Individual Psychological Behavior Mutation of Victims}

According to the cusp catastrophe model equilibrium surface of individual victim's psychological behavior in Figure 3 and the bifurcation set of cusp catastrophe model of individual victim's psychological behavior in Figure 4, after being rotated and simplified, and the visual graphs of Figures 3 and 4 are drawn with the software Visio. Figure 4 is the projection of the fold surface in Figure 3 on the control surface, and the visual model of individual psychological behavior state evolution of the victims after the occurrence of natural disasters is obtained, as shown in Figure 5. This can analyze the causes, process and degree of individual psychological behavior of the victims. The balance surface in Figure 5 is divided into three parts: the upper, the middle and the lower leaf. The upper leaf represents the calm behavior of the victims, the lower leaf represents the panic behavior of the victims. The individual psychological behavior of the victims is relatively stable in the upper and lower leaves of the balance surface, and the middle leaf is an unstable state, i.e., the region where the individual psychological behavior of the victims suddenly changes.

When the change curve of individual psychological behavior of the victims in Figure 5 is $a \rightarrow b$ or $d \rightarrow e$, the perception distance of psychological state of the victims $\Delta x$ gradually increases, but it has not exceeded the psychological perception threshold, and the degree of calmness of the victims gradually decreases. They become more and more irrational, which is still a gradual change, and no sudden change has occurred. When passing through points $b$ and $e$ respectively, the psychological behavior curve of the victims passes through bifurcation region $B$, which suddenly changes from calm to panic behavior. However, there are differences between the curves $f 1$ and $f 2$ projected to the set of control plane bifurcation points, which shows that the degree of panic caused by these two different behavior changes is different. When the state curve of psychological behavior of the victims is $b \rightarrow c, \Delta f 1=x\left(u_{b}, v_{b}\right)-x\left(u_{c}, v\right)$, while when the state curve of psychological behavior of the victims

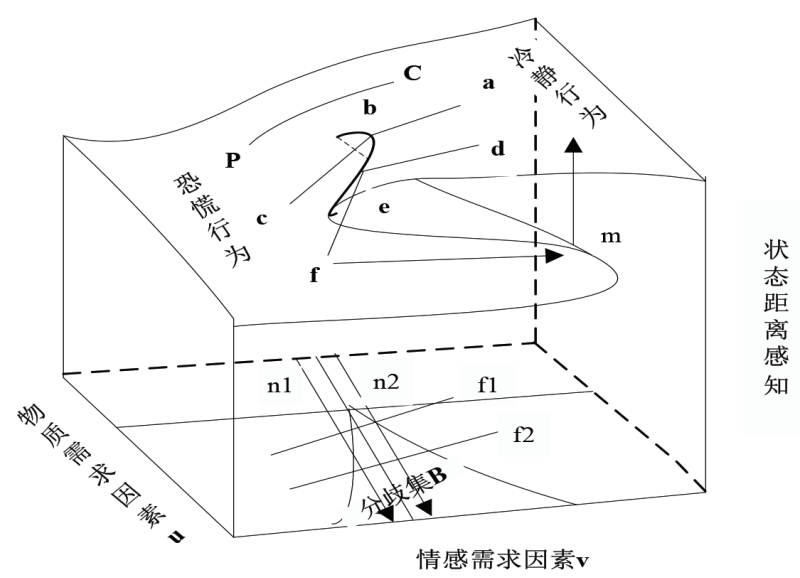

Figure 5 The intuitive evolution model of individual victim's psychological behavior of nature disaster during recovery stage. is $e \rightarrow f, \Delta f 2=x\left(u_{e}, v_{e}\right)-x\left(u_{\rho} v_{f}\right)$, and it is easy to find that $\Delta f 2>$ $\Delta f 1$ through the bifurcation set of the control surface, which indicates that the harm degree of the curve of psychological behavior $d \rightarrow e \rightarrow f$ is more serious. At this time, the psychological behavior of the victims may be looting materials, conflicting with others or even group affairs. When the psychological behavior curve is $a \rightarrow$ $b \rightarrow c$, the victims may only panic and wait for rescue passively, which does not pose a great threat to social stability and order.

Through the analyses above, it can be seen that when the material and emotional needs of the victims are constantly changing, the psychological behavior of the victims will jump from calm to panic behavior, which poses a huge threat to the stability and order of the society, but the material and emotional needs factors have different effects on the psychological behavior of the victims. There are two situations to discuss:

(1) Case 1: when the material demand of the victims is greater than zero, i.e., when $u>0,8 u^{3}+27 v^{2}>0$, formula (4) has no solution, and the individual psychological behavior curve of the victims does not go through bifurcation set. With the continuous change of $v$, the psychological behavior state of the victims is only continuous change, and there is no jump phenomenon;

(2) Case 2: when the individual material demand of the victims is not more than zero, i.e., when $u \leq 0,8 u^{3}+27 v^{2} \leq 0$, the formula (4) has a solution. From Figure 4 it can be seen that when $v$ gradually changes from -1 to +1 , the psychological behavior curve of the victims passes through the bifurcation set, and the psychological behavior state of the victims suddenly jumps.

According to the catastrophe theory, the degree of material demand satisfaction $u$ is the splitting factor, i.e., the change of $u$ will split the balance surface $M$ and produce different states, which determines whether the psychological behavior of the victims will suddenly change. As shown in Figure 5, when the material demand satisfaction reaches a relatively high level, i.e., when $u$ is close to 1 , with the continuous change of emotional demand satisfaction, the individual psychological behavior curve $\mathrm{CP}$ of the victims changes continuously from the upper leaf of the balance surface to the lower leaf, and its projection on the control surface does not go through the bifurcation set, indicating that the calm level of the victims is becoming gradually lower, but it will not suddenly evolve into an irrational threat to social stability, which is going to take a while, while emotional demand factor $v$ is a regular factor, i.e., when $u>0$, the change of $v$ only causes the smooth change of state variables. Through Figures 4 and 5, it can be seen that when the satisfaction degree of material demand $u$ decreases to 0 , the slight change of emotional demand factor $v$ will produce different behavior paths $n 1$ and $n 2$. The $n 1$ curve reaches the lower leaf of the balance surface through the bifurcation region, resulting in panic behavior, while the $n 2$ curve reaches the upper leaf of the balance surface through the bifurcation region, resulting in calm behavior.

\section{LOCAL VERIFICATION OF POINT MUTATION MODEL OF INDIVIDUAL PSYCHOLOGICAL BEHAVIOR OF VICTIMS}

Under the natural disaster situation, the individual psychological behavior mutation of the victims is instantaneous and dynamic, and its mutation process is difficult to capture. It is difficult to 
describe the cusp mutation process of the individual psychological behavior of the victims with the actual data. This paper uses the method of questionnaire survey to locally verify the two control variable types of material demand and emotional demand, and illustrates the validity of the model.

In this study, the disaster victims in Lushan County were randomly sampled and investigated. A total of 405 questionnaires were issued and 306 effective questionnaires were recovered. The effective rate of the questionnaire was $75.5 \%$. The psychological behaviors of the victims were measured by PCL-C, Post-traumatic Stress Disorder (PTSD) can not only reflect the psychological state of the victims (such as fidgety and depression), but also reflect the behaviors of the victims [53]. The higher the score is, the more likely it is to represent PTSD. This scale has been used for PTSD measurement after disasters for many times, with good reliability and validity [54]. Social support, social trust and social network are used to measure the relationship between the emotional needs of the victims and PTSD. Likert 5-point scale is used in this part of the questionnaire. The larger the number is, the more emotional support is obtained. The lower the income is, the poorer the family is. Thus the greater the social vulnerability is, which makes the economic endurance worse, impairing the ability to cope with the disaster, and rising the degree of material demand after the disaster [55]. Therefore, the relationship between material demand and PTSD can be measured by the level of income. According to the average monthly income level of local disaster victims, it can be divided into five levels: $1=$ 1000 yuan or less, $2=1001-2000$ yuan, $3=2001-3000$ yuan, $4=$ $3001-4000$ yuan, $5=4000$ yuan or more. The higher the total score of PTSD is, the more obvious the symptoms of PTSD is. In order to describe the relationship between income, emotional support and PTSD, 306 victims were divided into five groups according to income level and emotional support with SPSS19.0, and the mean value of PTSD in each group was obtained, then the scatter diagram of income level and PTSD's mean value was drawn, as shown in Figure 6; the scatter diagram of social network and PTSD's mean value was drawn, as shown in Figure 7; the scatter diagram of social support and PTSD's mean value was drawn, as shown in Figure 8; the scatter diagram of social trust level and PTSD's mean value, as shown in Figure 9. It can be seen from Figure 6 that with the increase of the monthly average income level, the PTSD's mean value gradually decreases, but when the monthly average income reaches 3000 yuan, the PTSD's mean value suddenly decreases, the psychological behavior of the victims has changed obviously. From Figures 7-9, it can be seen that the average value of PTSD gradually decreases

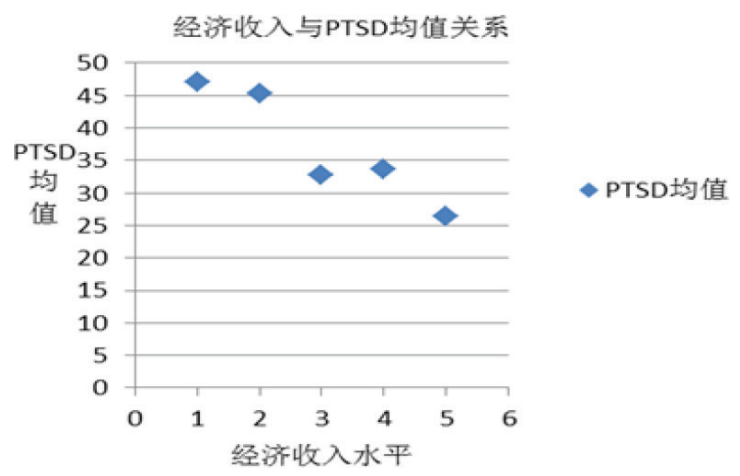

Figure 6 Scatterplot of income level and the average of PTSD.

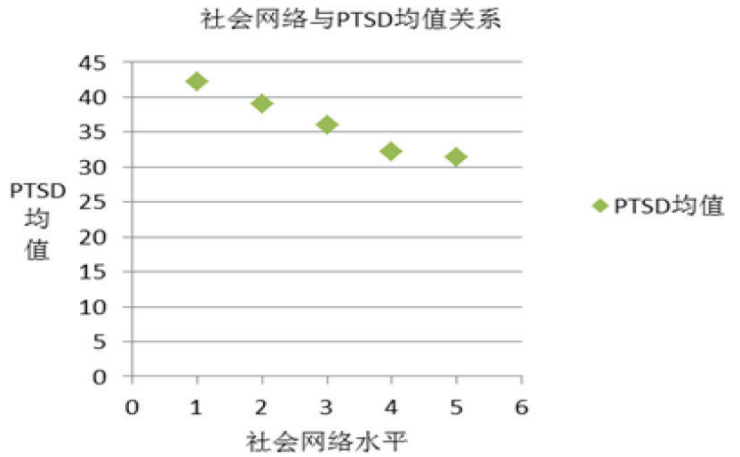

Figure 7 Scatterplot of social network level and the average of PTSD.

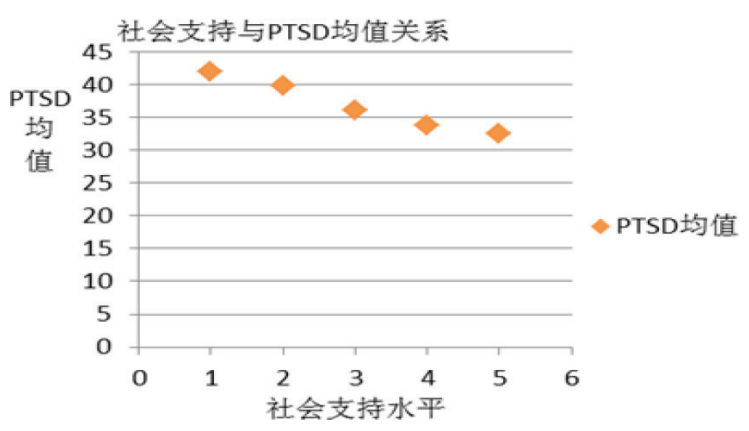

Figure 8 Scatterplot of social support level and the average of PTSD.

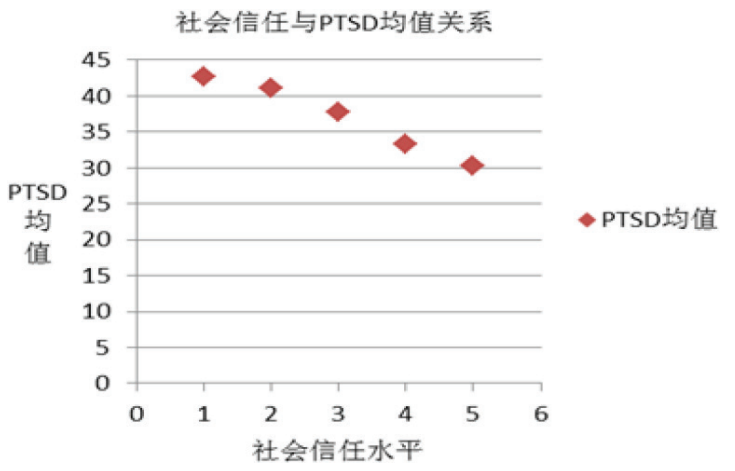

Figure 9 Scatterplot of social trust level and the average of PTSD.

with the improvement of social network, social support and social trust, but the change of emotional support level and the average value of PTSD presents a linear relationship without sudden jumps, the mutation of the system happens only because of the change of material demand. This shows that it is basically in line with the actual situation to regard the material demand satisfaction as the splitting factor and the emotional demand satisfaction as the regular factor. This is also basically consistent with Maslow's theory of demand level: People's needs are divided into different levels. Only when the needs of the bottom are met, people will pay attention to the needs of the higher level. After the occurrence of natural disasters, the greatest threaten people are facing is the threat of survival. People's most concerned needs are physiological needs and security needs. At the same time, people have social attributes, which need the communication between people to be met, especially in the post disaster psychological trauma period. 


\section{COPING STRATEGIES OF INDIVIDUAL PSYCHOLOGICAL BEHAVIORS OF VICTIMS}

Two to three months after the occurrence of natural disasters, the disaster area began to recover slowly. The affected people's emotions were relatively stable, sometimes they would be very rational and actively involved in the post disaster reconstruction work, but sometimes they would suddenly become irrational, have some conflicts with others, or even group affairs, which was not only related to personal characteristics, but also affected by the demand factors of people at that time. The psychological trauma of the victims is shown in the way of behavior under the influence of demand factors. Through the analysis above, it can be seen that the needs of the victims should be fully met in this period, but the priority and degree of these needs are different.

(1) Establish a perfect distribution and transportation system of rescue materials to ensure that the victims receive rescue materials as soon as possible. Through the analysis above, it can be seen that the satisfaction degree of material demand determines whether the psychological behavior of the victims will change suddenly. When the satisfaction degree of material demand $u>0$, the psychological behavior of the victims will only change continuously, and will not change into panic behavior through the bifurcation set. However, when $u$ gradually reaches 0 , the psychological behavior curve of the victims will go through the bifurcation set, and the psychological behavior will jump. Therefore, in the first time after the disaster, we should meet the material needs of the victims through various ways, especially for the low-income people, reduce their relative sense of deprivation in terms of materials, and improve the disaster response ability and economic endurance.

(2) Establish a lasting psychological intervention mechanism and provide a sound emotional support system. In the post disaster recovery period, people not only care about their own food, clothing, housing and transportation, but also have emotional needs which are to be cared and concerned. Natural disasters bring huge economic losses and mental trauma to the victims, often lacking confidence and courage in reconstruction. At this time, the government and people from all walks of life need to provide certain emotional support to help the victims recover their confidence in reconstruction. Through the above analysis, we can also see that when the material needs of the victims are gradually reduced to 0 , the small changes in emotional needs can lead to completely different behavioral responses of the victims. Therefore, in the post disaster recovery period, we should also attach great importance to the emotional needs of the victims, and make full use of various resources to help the victims recover social networking.

\section{CONCLUSION}

In the period of natural disaster recovery, the victims sometimes show a high degree of rationality and actively invest in the post disaster reconstruction work, but sometimes they suddenly change from calm to panic behavior, or even conflict behavior. In view of this problem, this paper analyzes the influencing factors of the individual psychological behavior state of the victims based on the literatures and the investigations of the disaster area, constructs the catastrophe model of the individual psychological behavior of the victims by using the catastrophe theory, depicts the intuitive model of the evolution of the individual psychological behavior state of the victims, probes into the catastrophe mechanism of the individual behavior of the victims. In addition, the model is partially verified by the actual survey data. Through the analysis, it is found that the satisfaction degree of material needs is the decisive factor of the psychological behavior mutation of the victims, and the satisfaction degree of emotional needs is the nondecisive factor of the psychological behavior mutation of the victims. However, when the satisfaction degree of material needs is low to zero, the slight change of emotional needs will make the victims produce different psychological behaviors. Therefore, it is necessary to establish a perfect distribution system of rescue materials to meet the material needs of the victims at the first time, and at the same time, the emotional needs of the victims cannot be ignored. It is necessary for the government to establish a lasting psychological intervention mechanism to provide sound emotional support for the victims in order to prevent the irrational behaviors caused by the minor emotional changes of the victims. Here, the following suggestions are put forward for relevant risk management professionals: in disaster prone areas, take families as a unit to investigate and count the mental health status of residents, such as the ability to resist stress, whether there are family members with severe PTSD, etc., and divide all families in disaster prone areas into "very healthy, healthy, general, serious and deadly serious" according to their mental health status, and archive them. In the same way, the economic income, social network, social trust and social support level are investigated one-by-one, and finally classified and archived. According to the conclusion of this study, the priority of material needs of the disaster victims is higher than their emotional needs. Therefore, we decided that the weight of the economic income level, mental health status, emotional needs factors (i.e. social network, social trust and social support level) reduce inturn in order to score the family. Among them, the weight of three influencing factors of emotional needs factors accounts for the same proportion. For example, $40 \%$ of the economic income level, $30 \%$ of the mental health status, $10 \%$ of the social network level, $10 \%$ of the social trust level and $10 \%$ of the social support level (the relevant risk management professionals can make a second decision in the future). The higher the score of a single family is, the higher the material demand is, and the lower the score is, the more emotional intervention the family needs. In this way, the government can help different families in different situations in the first time after the disaster, in order to strive for the stability and harmony of the whole society. In terms of resource allocation for disaster recovery, we can also see the level of material demand of each family in the database according to their scores, so as to determine the degree of subsidy to their economy. Although this paper analyzes the mutation mechanism of the individual psychological behavior of the victims, the verification of the model has limitations. It needs to consider the interaction of individual characteristics (such as age, gender, education level, etc.), information dissemination, government psychological intervention, population density, social structure, disasters' type and other factors on the evolution of the psychological behavior of the victims. At the same time, the research data in this paper is limited, and a large number of empirical data are still needed to further verify in the future. 


\section{CONFLICTS OF INTEREST}

The authors declare they have no conflicts of interest.

\section{ACKNOWLEDGMENT}

This research is supported by grants from the Project of National Nature Science Foundation of China (71671189, 71971217).

\section{REFERENCES}

[1] Ministry of Civil Affairs. The basic situation of nationwide natural disasters in 2014. Available from: http://www.mca. gov.cn/article/zrzh/201412/index.htm\# [20 January 2015] (In Chinese).

[2] Cameron L, Shah M. Risk-taking behavior in the wake of natural disasters. National Bureau of Economic Research (NBER). J Hum Res 2015;50:484-515.

[3] Kunimatsu MM, Marsee MA. Examining the presence of anxiety in aggressive individuals: the illuminating role of fight-or-flight mechanisms. Child Youth Care Forum 2012;41:247-58.

[4] Zhengkui L, Kankan W, Li W. Psychological and behavioral research after major disaster in China. Adv Psychol Sci 2011;19:1091-8 (In Chinese).

[5] Hu ZH, Sheu JB. Post-disaster debris reverse logistics management under psychological cost minimization. Transport Res Part B Methodol 2013;55:118-41.

[6] Rennemo SJ, Rø KF, Hvattum LM, Tirado G. A three-stage stochastic facility routing model for disaster response planning. Transport Res Part E Logistics Transport Rev 2014;62:116-35.

[7] Chae J, Thom D, Jang Y, Kim SY, Ertl T, Ebert DS. Public behavior response analysis in disaster events utilizing visual analytics of microblog data. Comput Graph 2014;38:51-60.

[8] Fan W. Advisement and suggestion to scientific problems of emergency management for public incidents. Bull Natl Nat Sci Found China 2007;21:71-6 (In Chinese).

[9] Doherty TJ, Clayton S. The psychological impacts of global climate change. Am Psychol 2011;66:265-76.

[10] Norris FH, Friedman MJ, Watson PJ, Byrne CM, Diaz E, Kaniasty K. 60,000 disaster victims speak: part I. An empirical review of the empirical literature, 1981-2001. Psychiatry 2002;65:207-39.

[11] Kõlves K, Kõlves KE, De Leo D. Natural disasters and suicidal behaviours: a systematic literature review. J Affect Disord 2013;146:1-14.

[12] Hu ZH, Sheu JB, Xiao L. Post-disaster evacuation and temporary resettlement considering panic and panic spread. Transport Res Part B Methodol 2014;69:112-32.

[13] Helbing D, Farkas I, Vicsek T. Simulating dynamical features of escape panic. Nature 2000;407:487-90.

[14] Huagui Z. Individual behavior in emergency decision-making. Impact Sci Soc 2008:31-7 (In Chinese).

[15] Bonanno GA, Galea S, Bucciarelli A, Vlahov D. What predicts psychological resilience after disaster? The role of demographics, resources, and life stress. J Consult Clin Psychol 2007;75:671-82.

[16] van der Linden S. The social-psychological determinants of climate change risk perceptions: towards a comprehensive model. J Environ Psychol 2015;41:112-24.
[17] Akerlof K, Maibach EW, Fitzgerald D, Cedeno AY, Neuman A. Do people "personally experience" global warming, and if so how, and does it matter?. Glob Environ Change 2013;23:81-91.

[18] Vallacher RR, Nowak A. The emergence of dynamical social psychology. Psychol Inquiry 1997;8:73-99.

[19] Thom R. Stabilité structurelle et morphogénèse. New York: Benjamin; 1972.

[20] Bode S. Catastrophe theory (translated by Fuhua L.). Shanghai: Shanghai Scientific and Technological Literature Press; 1983 (In Chinese).

[21] Zeeman EC. Catastrophe theory. In: Güttinger W, Eikemeier H, editors. Structural Stability in Physics. Berlin, Heidelberg: Springer; 1979, pp. 12-22.

[22] Stewart IN, Peregoy PL. Catastrophe theory modeling in psychology. Psychol Bull 1983;94:336-62.

[23] van der Maas HLJ, Kolstein R, van der Pligt J. Sudden transitions in attitudes. Socio Methods Res 2003;32:125-52.

[24] Scott DW. Catastrophe theory applications in clinical psychology: a review. Curr Psychol Res Rev 1985;4:69-86.

[25] Flay BR. Catastrophe theory in social psychology: some applications to attitudes and social behavior. Behav Sci 1978;23:335-50.

[26] Lu J, Lianyu Y. The application of primary catastrophe theory to social science. Syst Eng Theor Pract 2002;10:3-5 (In Chinese).

[27] Xu Z, Bin H. Research on staff counterproductive work behaviors based on catastrophe theory. J Manage Sci 2012;25:44-55 (In Chinese).

[28] Exiang L, Hong Y, Xingsan Q. An application of catastrophe theory to employees' behaviors of organizational change. Sci Technol Prog Policy 2007;23:181-3 (In Chinese).

[29] Xu Z, Bin H. Research on conflict behavior between enterprises and employees based on catastrophe theory and evolutionary game. Oper Res Manage Sci 2014;23:228-37 (In Chinese).

[30] Yan X, Bin H, Yongqing Y. A stochastic catastrophe model of knowledge sharing with in a team including simulations. Oper Res Manage Sci 2013;22:240-9 (In Chinese).

[31] Hu B, Xia N. Cusp catastrophe model for sudden changes in a person's behavior. Inform Sci 2015;294:489-512.

[32] Yiu KTW, Cheung SO. A catastrophe model of construction conflict behavior. Build Environ 2006;41:438-47.

[33] Chen DG, Chen X, Tang W. Stochastic cusp catastrophe model and its sample size determination in social behavior research. In: Proceedings of the 142nd APHA Annual Meeting and Exposition. New Orleans, LA, USA: APHA; 2014.

[34] Castillo M, Carter M. Behavioral responses to natural disasters. 2011 (Unpublished Manuscript).

[35] Kan S. Disaster psychology. Sci Press 2010:16-50 (In Chinese).

[36] Vorst HCM. Evacuation models and disaster psychology. Proc Eng 2010;3:15-21.

[37] Defu M. Research on the disaster psychology and behavioral choices with bounded rationality of farmers. HuBei Soc Sci 2010:76-8 (In Chinese).

[38] Huagui Z. Analysis on victims' panic behavior and influencing factors under emergency disaster situations. Academia Bimestris 2012:90-6 (In Chinese).

[39] Duoyong S. Study of individual and crowd behavior decision under paroxysmal social public crisis [D]. Changsha: Graduate school of national university of defense technology, 2005 (In Chinese).

[40] Ma QG, Wang XY. The mathematic description of the individual and crowd behavior under unconventional emergency. J Indus Eng Manag 2009;23:126-30 (In Chinese). 
[41] Sheeran P, Harris PR, Epton T. Does heightening risk appraisals change people's intentions and behavior? A meta-analysis of experimental studies. Psychol bull 2014;140:511-43.

[42] Milfont TL. The interplay between knowledge, perceived efficacy, and concern about global warming and climate change: a oneyear longitudinal study. Risk Anal 2012;32:1003-20.

[43] Spence A, Poortinga W, Pidgeon N. The psychological distance of climate change. Risk Anal 2012;32:957-72.

[44] Wachinger G, Renn O, Begg C, Kuhlicke C. The risk perception paradox-implications for governance and communication of natural hazards. Risk Anal 2013;33:1049-65.

[45] Sanduo Z, Chuanming C, LU Minghong. Management-Principles and Methods $[M]$. Shaihai: Fudan University Press; 2009, pp. 69-80 (In Chinese).

[46] Huijuan D, Xiaojun L, Manqing D, et al. Study on problems related to earthquake disaster-caused

[47] Li-Ping J, Lan Y, Yu-Ling W, Yi-Ting W, Wei-Qiong J. Qualitative research of survivors' cognition and psychological problems after Saomai Typhoon. Chinese Mental Health Journal 2008;929-33 (In Chinese).

[48] Yanna S, Wangyuhai, Jianhui L. Preliminary study of demand model of disaster relief and Its
[49] Dynes RR, Quarantelli EL, Kreps GA. A perspective on disaster planning[R]. Ohio State Univ Columbus Disaster Research Center; 1972.

[50] Naylor R, Courtney P. Exploring the social context of risk perception and behaviour: farmers' response to bovine tuberculosis. Geoforum 2014;57:48-56.

[51] Becker G, Aerts JCJH, Huitema D. Influence of flood risk perception and other factors on risk-reducing behaviour: a survey of municipalities along the Rhine. J Flood Risk Manag 2014;7:16-30.

[52] 李智明,师恪.证券收益的尖点突变模型 [J].新疆大学学报(自 然科学版) 2003;125-9.

[53] Yingjun X, Guoyu X, Yingqiang D, et al. Prevalence of posttraumatic stress disorder symptoms among middle school students after Wenchuan earthquake. Chinese Mental Health Journal 2010;17-20 (In Chinese).

[54] Weathers FW, Litz BT, Herman DS, et al. The PTSD Checklist (PCL): Reliability, validity, and diagnostic utility[C]//Annual Convention of the International Society for Traumatic Stress Studies. San Antonio: International Society for Traumatic Stress Studies; 1993.

[55] Cutter SL, Boruff BJ, Shirley WL. Social vulnerability to environmental hazards. Social science quarterly 2003;84:242-61. 